\title{
Training of Foreign Students in Verbal-Nominal Combinations in Different Spheres of Functioning
}

\author{
Arkadyeva Tatyana Grigoryevna ${ }^{1}$, \\ Professor of the department of Russian as foreign, Herzen State Pedagogical \\ University of Russia, \\ St.Petersburg, Russia. \\ Vasilyeva Marina Ivanovna; Vladimirova Svetlana Semenovna; Fedotova \\ Nadezhda Sergeyevna; Sharri Tatyana Germanovna \\ Associate professors of Russian as foreign, Herzen State Pedagogical University of \\ Russia, \\ St.Petersburg, Russia. \\ (date of receiving: August 2017; date of acceptance: November 2017)

\begin{abstract}
In this article, authors talk about the relevance of the training of foreign students in verbal-nominal combinations in different spheres of functioning. It is important for language adaptation. Language adaptation depends on how students know the system of language and the feature of language expression of sense. Verbal-nominal combinations are used in different spheres therefore they can be studied at the phonetic, lexical, phraseological, grammatical levels. Authors pay attention to the development of foreign students of abilities to differentiate the free, steady, phraseological verbal-nominal combination. Authors offer standard tasks that have already been practiced in occupations in foreign audiences. It is especially important to use language exercises for studying verbal-nominal combinations at the first stage of studying the language. At the second stage it is necessary to use communicative exercises more. Such an approach helps to form foreign students with the ability to analyze language material.
\end{abstract}

Keywords: Verbal-Nominal Phrases, Language Exercises, Communicative Exercises, Russian as Foreign, Language Adaptation.

1. E-mail: kafrki@mail.ru 


\title{
Обучение иностранных студентов глагольно-именным сочетаниям в разных сферах функционирования
}

\author{
Аркадьева Татьяна Григорьевна ${ }^{1}$
}

Профессор кафедры русского языка как иностранного РГПУ им. А.И. Герцена, Санкт-Петербург, Россия.

\section{Васильева Марина Ивановна; Владимирова Светлана Семеновна; Федотова Надежда Сергеевна; Шарри Татьяна Германовна.}

Доценты кафедры русского языка как иностранного РГПУ им. А.И. Герцена, Санкт-Петербург, Россия.

(дата получения: август 2017 г.; дата принятия: ноябрь 2017 г.)

\begin{abstract}
Аннотация
В статье обоснована необходимость обучения иностранных студентов глагольноименным сочетаниям в разных сферах функционирования. Это важно в аспекте языковой адаптации, так как она связана не только с овладением иностранными студентами системой языка, но и особенностями языкового выражения смысла. Глагольно-именные сочетания в системе русского языка представляют собой разнородный по структуре, семантике и сферам функционирования лексикограмматический материал. Глагольно-именные сочетания используются в разных сферах, в связи с чем их можно рассматривать на фонетическом, лексическом, фразеологическом, грамматическом уровнях. Обращается внимание на целесообразность развития у иностранных студентов умений различать свободные, устойчивые, фразеологизированные глагольно-именные сочетания, понимать их сходство и различие. Предлагаются типовые задания, которые апробированы на занятиях в иностранной аудитории. Подчеркивается важность языковых упражнений для овладения глагольно-именными сочетаниями на начальном этапе изучения языка и преобладание коммуникативных упражнений на продвинутом этапе. Такая дифференциация целесообразна, так как помогает выработать у иностранных студентов умения анализировать языковой материал.
\end{abstract}

Ключевые слова: Глагольно-Именные Словосочетания, Языковые Упражнения, Коммуникативные Упражнения, Русский Язык Как Иностранный, Языковая Адаптация.

1.E-mail:kafrki@mail.ru 


\begin{abstract}
Введение
В современном образовательном процессе значительное внимание уделяется адаптационным процессам, связанным с обучением иностранных студентов в российских вузах. Адаптационные характеристики личности включают в себя не только социальные, психологические аспекты, но и языковую адаптацию как процесс обогащения и развития языковой личности средствами языка, обеспечивающий реализацию целенаправленного речевого поведения, микро- и макросоциального взаимодействия в инокультурной среде при достижении личностного комфорта. Говоря о языковой адаптации, мы имеем в виду не только овладение иностранными обучающимися системными явлениями русского языка, но их функциональными языковыми характеристиками. Глагольно-именные сочетания используются в разных сферах, в связи с чем их можно рассматривать на фонетическом, лексическом, фразеологическом, грамматическом уровнях. В данной статье глагольноименные словосочетания рассматриваются в аспекте их предъявления в разных сферах иностранным студентам с разным уровнем владения русским языком.
\end{abstract}

\title{
Основная часть
}

Глагольно-именные сочетания в системе русского языка представляют собой разнородный по структуре, семантике и сферам функционирования лексико-грамматический материал: В конще предложения Лариса поставила точку. Компромисс поставил точку в конфликте этих кампаний. Мы должнь поставить все точки над и. Роман - очень хороший инженер. Он на этом деле собаку съел. Игорь настоящий друг. Мы с ним пуд соли съели. За год кролики съели 200 килограммов зеленой травы. Расходы кампании съели 20\% ее дохода. Если хочется съесть торт, ешьте его на здоровье! Они широко востребованы в практике обучения русскому языку как иностранному, так как правила построения словосочетаний по типу глагол+существительное весьма 
разнообразны и довольно сложны. «устойчивые глагольно-именные сочетания хотя и «синтаксичны» по структуре (являются словосочетаниями), по значению же они «лексикологичны» (выражают единый смысл), а в грамматическом плане «морфологичны», поскольку несут морфологические признаки наклонения, времени, лица и на правах аналитических лексем пополняют категорию глагола» (Гайсина 2012. 464).

В научно-методической литературе обращается внимание на «глагольноименные описательные сочетания, соотносимые с однокоренными глаголами, в плане грамматической семантики типа быть на службе у кого-либо служить кому-либо, вести строчтельство - строить, вести спор спорить, находиться в заблуждении - заблуждаться, находиться в зависимости от кого-либо - зависеть от кого-либо, предаваться воспоминаниям - вспоминать» (Ефремова 2009. 33), «модально-оценочные значения высказываний, обусловленные синтагматикой описательного глагольно-именного оборота (типа совершить преступление, сделать подлость и т.п.), употребление которых в языке печатных СМИ отражает тенденцию к экспрессивизации газетного текста» (Лагузова 2010. 590), «описательно-именные обороты в функциональном аспекте как одно из возможных средств экспликации модальных значений предиката, наслаивающихся на значение объективной модальности предложения» (Олзоева 2012. 44). Объектом рассмотрения лингвистов являются «устойчивые глагольно-именные сочетания, употребляющиеся в текстах древнерусских грамот и княжеских уставов XI-XIV веков» (Макушина 2010. 73), «классификации глагольных аналитических единиц, выработанные с использованием, функционального и семантического подходов» (Лобанова 2013. 163), «сопоставительное изучение русских глагольно-именных устойчивых словосочетаний (УС и способы их передачи на персидский язык» (Рахбари. 2014. 40). 
Трудности овладения глагольно-именными сочетаниями по мере изучения РКИ возрастают в связи с тем, что на различных этапах освоения русского языка иностранные студенты получают более широкий объем лексикограмматической и стилистический информации о данном типе словосочетаний: принять гостей, принять участие (ТРКИ-І), принять меры (ТРКИ-ІІ); привести ребенка в детский сад (ТРКИ-І), привести веские аргументы, привести убедительный пример (ТРКИ-ІІ); искать потерянный ключ, искать выход из метро (ТРКИ-І), искать выход из трудной ситуации (ТРКИ-ІІ). Несмотря на то что методика обучения РКИ на сегодняшний день располагает работами, посвященными глагольно-именным сочетаниям (Шатилов 1991; Тхумдала 1996; Бабаян 1984; Дерягина 2011; Клепацкая 2010), в ней еще остаются вопросы, важные для научного поиска, в том числе вопрос об обучении иностранных студентов глагольно-именным сочетаниям в разных сферах и на разных этапах.

На начальном этапе обучения иностранным студентам представлены свободные глагольно-именные сочетания (писать письмо, петь песню, играть на пианино, жить в городе и т.п.). Они по мере коммуникативных потребностей каждый раз создаются говорящим заново, и это не вызывает у обучающихся затруднений, так как слова употребляются в своих прямых номинативных значениях, а значение словосочетания представляет собой сумму значений его компонентов.

На среднем и продвинутом этапах обучения ситуация с восприятием и воспроизведением глагольно-именных сочетаний усложняется: сравните, ждать автобус и ждать у моря погоды, падать на пол и падать духом, остаться у подруги и остаться с носом, съесть яблоко и съесть пуд соли, положить в сумку $и$ положить под сукно. «Потребность вовлечения фразеологии в учебный процесс обусловлена тем, что без знания фразеологических единиц обучаемый не сможет стать полноценным и 
равноправным коммуникационным партнером; продвинутый этап обучения предполагает усвоение запаса фразеологических единиц, необходимого для того, чтобы обучаемый мог свободно пользоваться русским языком как иностранным в разных коммуникативных ситуациях, чтобы его речь отвечала узусу данного языка; обогащение русской речи иностранных учащихся является одной из важных задач методики преподавания РКИ, так как без умения пользоваться фразеологической сокровищницей русская речь не может считаться адекватной, неуместное употребление фразеологизмов искажает речь» (Олейник 2006. 4)

Учащимся предъявляются устойчивые глагольно-именные сочетания типа глагол+существительное (без предлога или с предлогом), которые широко употребляются в публицистическом, официально-деловом, научном стиле: Яркое солнце может нанести вред коже. Причина лишнего веса состоит в неправильном питании. Качество фотографии вызвало спор. Студенты не приступили к занятиям вовремя. С вопросом лучше обратиться 6 специальный отдел. Участники дискуссии пришли к выводу о необходимости заключить договор о сотрудничестве. Эти сочетания слов, обладают единством и постоянством лексического значения, образуются по определенной модели с ограниченным набором лексических компонентов и воспроизводятся в речи: бросаться - броситься в глаза, входить - войти во вкус, вертеться на языке, уходить - уйти в отставку, влезать - влезть в долги, пожимать - пожать плечами, сжигать - сжечь мость, терять потерять голову и т.д. Носители языка свободно пользуются широким разнообразием глагольно-именных сочетаний как свободных, так и устойчивых, в связи с тем что многие из них являются привычными с детства, а ряд других осознанно усваивается в процессе обучения в школе и освоения правил стилистики, культуры речи. Игорь скоро закончит школу и ему надо предпринимать какие-то шаги, чтобь подготовиться $\kappa$ поступлению 6 
университет. Тема дружбы проходит красной нитью в романе Л. Толстого «Война и мир». Куда поехать в отпуск? Не имеет значения. Я все равно нигде не был. Дорогие телезрители! Встретимся на телеканале «Россия» после рекламы и подведем итоги недели.

Ситуация у иностранных обучающихся более сложная. Иностранным студентам известно, что в русском языке слова соединяются в словосочетания. С этим материалом они знакомятся уже на первых занятиях по русскому языку: не будет автобуса, бояться темноты (Род. П.), звонить - позвонить родителям, помогать - помочь сестре, радоваться - обрадоваться подарку, удивляться - удивиться встрече (Дат. П.); пойти в библиотеку, покупать купить молоко, играть - сыграть в иахматы, учить - выучить слова, обсуждать - обсудить фильм, провожать - проводить друга, включать включить свет, продавать - продать автомобиль (Вин. П.); встречаться встретиться с одноклассниками, разговаривать с коллегой, здороваться поздороваться с преподавателем, знакомиться - познакомиться с девушкой (Твор. П.); мечтать о путешествии, жаловаться на трудности (Предл. П.). Последовательно изучается падежная система языка, запоминается объем глаголов, необходимых для общения на уровне учебной группы, магазина, дома, театра и т.д. (Государственный стандарт по русскому языку как иностранному. Базовый уровень 2001; Государственный стандарт по русскому языку как иностранному. Элементарный уровень 2001; Лексический минимум по русскому языку как иностранному. Базовый уровень 2011; Лексический минимум по русскому языку как иностранному. Первый сертификационный уровень 2011; Лексический минимум по русскому языку как иностранному. Элементарный уровень 2012; Программа по русскому языку для иностранных граждан. Первый сертификационный уровень 2011). Использование языковых упражнений на данном этапе освоения глагольно-именных сочетаний целесообразно, так как учащиеся всегда допускают ошибки в употреблении 
падежных форм или выборе глагола, нарушают правила лексической сочетаемости. Языковые упражнения, ориентированные на преобразование морфологических форм слова и формирующие навыки употребления этих единиц в соответствии с их лексическим значением, тренировку и автоматизацию языкового материала в значительно степени способствуют пониманию и запоминанию представленных в устном или письменном высказывании структурных элементов языка.

Задание 1. Прочитайте словосочетания. Поставьте слова в скобках в нужную форму. При необходимости используйте предлоги.

Роман изучает (грамматика). Цветы стоят (ваза). Анна учится (университет). Преподаватель исправляет (ошибки). Сергей Петрович работает (поликлиника). Мария рисует (карандаш).

Задание 2. Прочитайте вопросы. Дайте на эти вопросы полные ответы. Укажите как можно больше вариантов ответа.

1. Куда я могу положить свои вещи? 2. Посмотри, где лучше повесить картину? 3. Чем Вы любите писать? 4. Кому отвечает Иван Петрович?

Задание 3. Прочитайте предложения. Вместо точек вставьте необходимые по смыслу глаголы, выбрав один из предложенных вариантов ответа.

1. Дети... по телевизору фильм. а) смотрели б) думали.

2. Мы... из Москвы в 4 часа. а) приехали, б) доехали.

3. На концерт ... известный пианист. а) приехал, б) прибежал.

4. Туристы хотят ... музей. а) смотреть, б) осмотреть.

5. Сестра ... подарок Ольге. а) получила, б) подарила.

6. Нина занимается... а) музыкой, б) фруктами.

7. На уроке студенты .... трудное упражнение. а) говорили, б) делали.

8. До музея туристам надо... на автобусе. а) ехать, б) идти.

9. Борис повторил все ... а) экзамены, б) упражнения.

10. Лена не знает ... автора фильма. а) имя, б) название. 
11. Через 2 часа ... прилетел. а) самолёт, б) автобус.

12. Сын ... родителям хорошо учиться. а) обещал, б) советовал.

13. Детям нельзя долго... по телефону. а) говорить, б) работать.

Таким образом, тренировочные языковые упражнения предназначены для развития умений преодолевать трудности, связанные с особенностями семантики и употребления грамматических форм глагольно-именных сочетаний. В этих упражнениях процесс коммуникации (сфера повседневного общения) подчинен усвоению грамматических структур, лексических единиц, их морфологических изменений.

На продвинутом уровне увеличивается количество речевых и коммуникативных упражнений. (Государственный образовательный стандарт по русскому языку как иностранному. Второй уровень 199; Лексический минимум по русскому языку как иностранному. Второй сертификационный уровень 2011).

Языковые упражнения не отменяются, но в процентном соотношении их становится меньше. Используемая лексика соотносится со сферой профессионального общения (экономика, политика, юриспруденция, педагогика, архитектура, филология).

Задание 1. Прочитайте словосочетания, определите, в каких случаях они 1) совпадают в значении, 2) различаются стилистически, 3) различаются оттенками значений, 4) различаются в значении.

Выполнить работу в одну неделю - выполнить работу за одну неделю; готовить в кухне - готовить на кухне; стоять в углу - стоять на углу; лежать в кровати - лежать на кровати; жить в квартире - жить на квартире; растет в огороде - растет на огороде; ездить в городе - ездить по городам; гулять в лесу - гулять по лесу; навещать в праздники - навещать по праздникам; говорить в волнении - говорить с волнением; сгореть со стыда - сгореть от стыда; спускаться с лестницы - спускаться по лестнице. 
Задание 2. Поставьте существительные в скобках в нужной форме. Составьте с ними предложения.

Разбираться-разобраться (в чем?)

1. Роман хорошо разбирается в (компьютеры), (математика). Следователь хочет разобраться (причина аварии). Нам всем нужно разобраться в (то, что произошло).

Задание 3. Со следующими глаголами составьте словосочетания. Используйте слова для справок.

Обладать, обращать, оказывать, сыграть, придавать

Слова для справок: внимание, способности, помощь, значение, роль)

Данные языковые упражнения ориентированы на повторение грамматического материала, тренировку лексических и грамматических навыков.

Задание 4. Ответьте на вопросы.

Модель: - Почему ты хочешь стать волонтером? / - Потому что волонтерам предоставят возможность поступить в университет на бюджетные места.

1. Почему эта статья журналиста такая популярная? (предоставить новые факты). 2. Почему наша кампания заключила договор с этой фирмой? (пришли к компромиссу).

Задание 5. Составьте словосочетания со следующими глаголами в указанных значениях.

Играть... (1. проводить время в игре; 2. исполнять что-либо на музыкальном инструменте; 3. шалить, развлекаться).

Шутить... (1. говорить, делать что-либо так, чтобы было смешно; 2. делать предметом смеха, веселья; 3. относиться легкомысленно).

Жить... (1. проводить свою жизнь; 2. существовать, получая зарплату, пенсию и т.п.; 3. быть занятым, поглощенным, увлеченным чем-либо).

Задание 6. Придумайте реплики, высказывания, которые могут быть 
использованы в следующих ситуациях: 1. Вы беседуете с учениками на уроке. 2. Вы выступаете на педагогическом совете в школе. Употребите следующие глаголы. Обратите внимание на различия в управлении:

Вспоминать кого - что, о ком - о чем; думать о ком - о чем, над чем; забывать кого - что, о ком - о чем; знать кого - что, о ком - о чем; напоминать кого - что, кому о ком - о чем; помнить кого - что, о ком - о чем; упоминать кого - что, о ком - о чем.

Задание 7. Ответьте на вопросы, выбрав один из предложенных вариантов ответа.

1. Новый директор фирмы обещал сотрудникам... а) золотые поля, б) золотые горы, в) золотые реки. 2. Роман так увлекся математикой, что совсем ... а) потерял голову, б) потерял память, в) потерял себя. 3. Великолепное красное платье на витрине магазина сразу .... а) бросилось в глаза, б) бросилось в голову, в) бросилось в память.

Задание 8. Прочитайте первые реплики диалога, в состав которых входит устойчивое глагольное сочетание. Ответьте на эти реплики.

1. - Тебе не нужно изобретать велосипед.

$-\ldots$

2. - Сейчас сезонные скидки на зимнюю обувь. Лови момент!

$-\ldots$

3. - Хватит сгущать краски! На самом деле все было не так, как ты рассказываешь.

Задание 9. Вы находитесь в ситуации, когда Вы не согласны с тем, что Вам говорят. Возразите собеседнику.

Модель:

- Вы нарушили правила дорожного движения.

- Нет. Ну, что Вы! Я не нарушал правила дорожного движения, потому что я переходил улицу на зеленый свет. 
1. Вы слишком большое значение придаете своей внешности. 2. А сейчас мы может подвести итоги нашей встречи. 3. Наша кампания предоставляет услуги перевозки мебели. 4. Кампания гарантирует поставки продукции в указанный срок. 5. Эксперты проводят исследование нового рынка труда.

Задание 10. Ваши друзья просят Вас рассказать, как Вы изучали русский язык. Составьте рассказ, используйте в рассказе следующие свободные глагольно-именные сочетания и устойчивые глагольно-именные сочетания (на выбор): опустить руки, сорить деньгами, войти в привычку, прийти в восхищение, висеть на телефоне, защитить диссертацию, перевести роман, уйти на каникулы, осмотреть город, радоваться весне.

Коммуникативные упражнения в своей формулировке задания содержат коммуникативную задачу, которую иностранный студент должен решить, выразив свои мысли на русском языке с использованием глагольно-именных сочетаний. Коммуникативные упражнения обеспечивают формирование наиболее высокого уровня практического владения языком. При выполнении таких упражнений внимание студентов должно быть сосредоточено на содержании высказывания, а грамматическая форма является объектом непроизвольного внимания.

\section{Заключение}

Глагольно-именные сочетания - важная часть системы русского языка и открытый вопрос для методики преподавания русского языка как иностранного. Эти сочетания многочисленны и разнообразны. Находясь на границе фразеологии и грамматики, устойчивые глагольно-именные сближаются и с фразеологическими и синтаксическими единицами, что обусловливает неравноценность их подачи в иностранной аудитории в сравнении со свободными глагольно-именными сочетаниями. Поуровневое предъявление глагольно-именных сочетаний в иностранной аудитории, языковые и коммуникативные упражнения, демонстрирующие учащимся 
функционирование глагольно-именных сочетаний в разных сферах, помогают глубже понять специфику семантических и грамматических особенностей. Перспективой исследования может стать описание глагольно-именных сочетаний в разносистемных языках, выявление особенностей их функционирования в разных сферах. Важно определить, выступает ли глагол в качестве грамматически опорного слова в глагольно-именном сочетании, выражает ли он грамматические значения, подвергаются ли глаголы в глагольно-именных сочетаниях процессу десемантизации, существуют ли веские причины, чтобы разграничивать глагольно-именные фразеологические сочетания и устойчивые глагольно-именные сочетания.

\section{Литература}

1- Бабаян Т.А. (1984), Обогащение речи учащихся старших классов армянской школы устойчивыми глагольно-именными словосочетаниями. Автореферат диссертации на соискание ученой степени кандидата педагогических наук. M., 1984, 26 c.

2- Гайсина Р. М. (2012), Проблема взаимодействия имени и глагола в русской грамматической традииии ХІХ-ХХ вв. // Вестник Баикирск. Ун-та. 2012. № 1(I). C.460-464.

3- Государственный образовательный стандарт по русскому языку как иностранному. Второй уровень. Общее владение (1999) // Иванова Т. А. и др. М. СПб: Златоуст, 1999. — 40 c.

4- Государственный стандарт по русскому языку как иностранному. Базовый уровень (2001) // Нахабина М.М., Соболева Н.И. и др. СПб.: Златоуст, 2001. 32 c.

5- Государственный стандарт по русскому языку как иностранному. Элементарный уровень (2001) // Владимирова Т.Е., Нахабина М.М. и др. СПб.: Златоуст, 2001. 20 с.

6- Дерягина С.И. (2011), К вопросу о глагольно-именных словосочетаниях при обучении иностранных учашихся русскому языку // Актуальные проблемы гуманитарных и естественных наук. 2011. № 12. С. 100-103. 
7- Ефремова Э.И. (2009), Глагольно-именные описательные сочетания как выразители грамматической семантики // Вестник Новгородского государственного университета им. Ярослава Мудрого. 2009. № 54. С. 33-36.

8- Клепацкая Я.В. (2010), Совершенствование навыков построения $и$ употребления глагольно-именных словосочетаний в продуктивной речи. Автореферат диссертации на соискание ученой степени кандидата педагогических наук. - СПб., 2010, 22 с.

9- Лагузова Е.Н. (2010), Модально-оценочная семантика высказываний с описательными глагольно-именными оборотами // Вестник Нижегородского университета им. Н.И. Лобачевского. 2010. № 4-2. С. 590-592.

10- Лексический минимум по русскому языку как иностранному. Базовый уровень. Общее владение (2011)// Андрюшина Н.П. и др. - СПб.: Златоуст, 2011. 116 с.

11- Лексический минимум по русскому языку как иностранному. Второй сертификационный уровень (2011) //Андрюшина Н.П., Афанасьева И.Н., Битехина Г.А., Клобукова Л.П., Яценко И.И. - СПб.: Златоуст, 2011. 164 с.

12- Лексический минимум по русскому языку как иностранному. Первый сертификационный уровень. Общее владение (2011) // Андрюшина Н.П. и др. - СПб.: Златоуст, 2011. 200 с.

13- Лексический минимум по русскому языку как иностранному. Элементарный уровень. Общее владение (2012) // Андрюшина Н.П. и др. - СПб: Златоуст, 2012. 80 c.

14- Лобанова С.В. (2013), Классификация устойчивых глагольно-именных сочетаний в современном русском языке: подходы и проблемы // Вестник ТГПУ. 2013. №10 (138). С. 163-167

15- Макушина А.А. (2010), Семантическое взаимодействие компонентов устойчивых глагольно-именных сочетаний в древнерусском деловом языке // Вестник ВолГУ. Серия 2: Языкознание. 2010. № 2-12. С. 73-76.

16- Олейник М.А. (2006), Обучение иностранных студентов-гуманитариев русским фразеологизмам. Автореферат диссертации на соискание ученой степени кандидата педагогических наук. - СПб., 1991, 22 с.

17- Олзоева Я.В. (2012), Описательные глагольно-именные обороты как средство выражения внутрисинтаксической модальности возможности в современном русском языке // Учёные записки ЗабГУ. Серия: Филология, история, востоковедение. 2012. № 2. С. 44-48. 
18- Программа по русскому языку для иностранных граждан. Первый сертификационный уровень. Общее владение (2011) // Андрюшина Н.П. и др. - СПб: Златоуст, 2011. 176 с.

19- Рахбари Махназ, Валипур Алиреза (2014), Сопоставительное изучение способов передачи русских глагольно-именных устойчивых словосочетаний при обучении русскому языку как иностранному иранских учашихся // Вестник ЮУрГУ. Серия: Лингвистика. 2014. № 1. С. 40-44

20- Тхумдала (1996), Методика обучения лаосских учащихся владению глагольноименными словосочетаниями русского языка (на материале начальнобазового курса). Автореферат диссертации на соискание ученой степени кандидата педагогических наук. - М., 1996, 26 с.

21- Шатилов А.С. (1991), Обучение иностранных аспирантов нефилологических специальностей владению глагольно-именными словосочетаниями в устной речи на начальном этапе. Автореферат диссертации на соискание ученой степени кандидата педагогических наук. - СПб., 1991, 22 с.

\section{Bibliography}

1- Babajan T.A. (1984), Obogashhenie rechi uchashhihsja starshih klassov armjanskoj shkoly ustojchivymi glagol'no-imennymi slovosochetanijami. Avtoreferat dissertacii na soiskanie uchenoj stepeni kandidata pedagogicheskih nauk. - M., 1984, 26 s.

2- Gajsina R. M. (2012), Problema vzaimodejstvija imeni $i$ glagola v russkoj grammaticheskoj tradicii HIH-HH vv. // Vestnik Bashkirsk. Un-ta. 2012. № 1(I). S.460-464.

3- Gosudarstvennyj obrazovatel'nyj standart po russkomu jazyku kak inostrannomu. Vtoroj uroven'. Obshhee vladenie (1999) // Ivanova T. A. i dr. M. SPb: Zlatoust, 1999. $-40 \mathrm{~s}$.

4- Gosudarstvennyj standart po russkomu jazyku kak inostrannomu. Bazovyj uroven' (2001) // Nahabina M.M., Soboleva N.I. i dr. SPb.: Zlatoust, 2001. 32 s.

5- Gosudarstvennyj standart po russkomu jazyku kak inostrannomu. Jelementarnyj uroven' (2001) // Vladimirova T.E., Nahabina M.M. i dr. - SPb.: Zlatoust, 2001. $20 \mathrm{~s}$.

6- Derjagina S.I. (2011), K voprosu o glagol'no-imennyh slovosochetanijah pri obuchenii inostrannyh uchashhihsja russkomu jazyku // Aktual'nye problemy gumanitarnyh i estestvennyh nauk. 2011. № 12. S. 100-103. 
7- Efremova Je.I. (2009), Glagol'no-imennye opisatel'nye sochetanija kak vyraziteli grammaticheskoj semantiki // Vestnik Novgorodskogo gosudarstvennogo universiteta im. Jaroslava Mudrogo. 2009. № 54. S. 33-36.

8- Klepackaja Ja.V. (2010), Sovershenstvovanie navykov postroenija i upotreblenija glagol'no-imennyh slovosochetanij $v$ produktivnoj rechi. Avtoreferat dissertacii na soiskanie uchenoj stepeni kandidata pedagogicheskih nauk. - SPb., 2010, 22 s.

9- Laguzova E.N. (2010), Modal'no-ocenochnaja semantika vyskazyvanij s opisatel'nymi glagol'no-imennymi oborotami // Vestnik Nizhegorodskogo universiteta im. N.I. Lobachevskogo. 2010. № 4-2. S. 590-592.

10- Leksicheskij minimum po russkomu jazyku kak inostrannomu. Bazovyj uroven'. Obshhee vladenie (2011)// Andrjushina N.P. i dr. - SPb.: Zlatoust, 2011. 116 s.

11- Leksicheskij minimum po russkomu jazyku kak inostrannomu. Vtoroj sertifikacionnyj uroven' (2011) //Andrjushina N.P., Afanas'eva I.N., Bitehina G.A., Klobukova L.P., Jacenko I.I. - SPb.: Zlatoust, 2011. 164 s.

12- Leksicheskij minimum po russkomu jazyku kak inostrannomu. Pervyj sertifikacionnyj uroven'. Obshhee vladenie (2011) // Andrjushina N.P. i dr. - SPb.: Zlatoust, 2011. $200 \mathrm{~s}$.

13- Leksicheskij minimum po russkomu jazyku kak inostrannomu. Jelementarnyj uroven'. Obshhee vladenie (2012) // Andrjushina N.P. i dr. - SPb: Zlatoust, 2012. $80 \mathrm{~s}$.

14- Lobanova S.V. (2013), Klassifikacija ustojchivyh glagol'no-imennyh sochetanij v sovremennom russkom jazyke: podhody i problemy // Vestnik TGPU. 2013. №10 (138). S. 163-167

15- Makushina A.A. (2010), Semanticheskoe vzaimodejstvie komponentov ustojchivyh glagol'no-imennyh sochetanij $v$ drevnerusskom delovom jazyke // Vestnik VolGU. Serija 2: Jazykoznanie. 2010. № 2-12. S. 73-76.

16- Olejnik M.A. (2006), Obuchenie inostrannyh studentov-gumanitariev russkim frazeologizmam. Avtoreferat dissertacii na soiskanie uchenoj stepeni kandidata pedagogicheskih nauk. - SPb., 1991, $22 \mathrm{~s}$.

17- Olzoeva Ja.V. (2012), Opisatel'nye glagol'no-imennye oboroty kak sredstvo vyrazhenija vnutrisintaksicheskoj modal'nosti vozmozhnosti $v$ sovremennom russkom jazyke // Uchjonye zapiski ZabGU. Serija: Filologija, istorija, vostokovedenie. 2012. № 2. S. 44-48. 
18- Programma po russkomu jazyku dlja inostrannyh grazhdan. Pervyj sertifikacionnyj uroven'. Obshhee vladenie (2011) // Andrjushina N.P. i dr. - SPb: Zlatoust, 2011. $176 \mathrm{~s}$.

19- Rahbari Mahnaz, Valipur Alireza (2014), Sopostavitel'noe izuchenie sposobov peredachi russkih glagol'no-imennyh ustojchivyh slovosochetanij pri obuchenii russkomu jazyku kak inostrannomu iranskih uchashhihsja // Vestnik JuUrGU. Serija: Lingvistika. 2014. № 1. S. 40-44

20- Thumdala (1996), Metodika obuchenija laosskih uchashhihsja vladeniju glagol'noimennymi slovosochetanijami russkogo jazyka (na materiale nachal'no-bazovogo kursa). Avtoreferat dissertacii na soiskanie uchenoj stepeni kandidata pedagogicheskih nauk. - M., 1996, $26 \mathrm{s.}$

21- Shatilov A.S. (1991), Obuchenie inostrannyh aspirantov nefilologicheskih special'nostej vladeniju glagol'no-imennymi slovosochetanijami v ustnoj rechi na nachal'nom jetape. Avtoreferat dissertacii na soiskanie uchenoj stepeni kandidata pedagogicheskih nauk. - SPb., 1991, 22 s.

\section{HOW TO CITE THIS ARTICLE}

Arkadyeva T.G. et al. (2018). Training of Foreign Students in

Verbal-Nominal Combinations in Different Spheres of Functioning, Issledovatel'skiy Zhurnal Russkogo Yazyka i Literatury, 11(1): pp:27-43.

DOI: $10.29252 /$ iarll.11.27

URL: http://journaliarll.ir/article-1-128-en.html

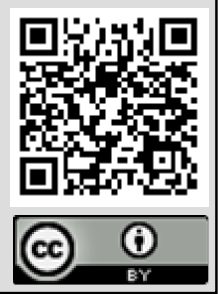




\section{آموزش كاربردهاى گوناگون تركيبات فعل و اسم براى دانشجويان خارجى}

$$
\begin{aligned}
& \text { تاتيانا گريخارييونا آر كادييوا' } \\
& \text { استاد كروه زبان روسى به عنوان زبان خارجى دانشكاه دولتى علوم تربيتى آ.ایى كر تسن روسيه، }
\end{aligned}
$$

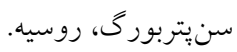

مارينا ايوانونا واسيلى يوا؛ سو تلانا سيميونونا ولاديميرووا؛ نادزدا سر كئى يونا فيدوتاوا؛ تاتيانا كرمانونا شارى

دانشياران كروه زبان روسى به عنوان زبان خارجى دانشخاه دولتى علوم تربيتى آ.اى. كرتسن روسيه،

$$
\text { سنيتربورگ، روسيه. }
$$

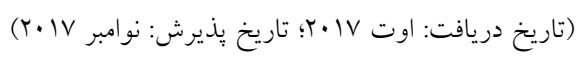

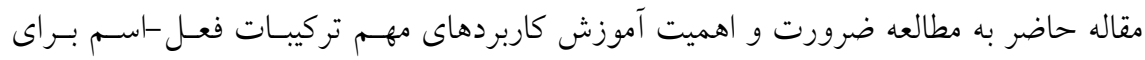

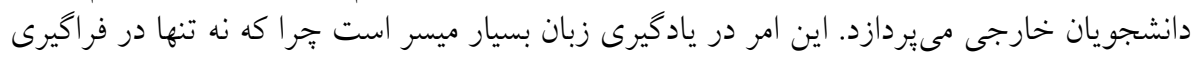

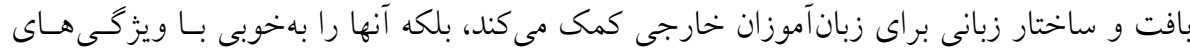

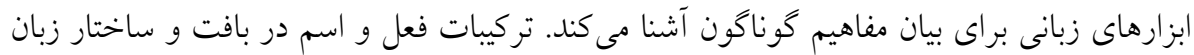

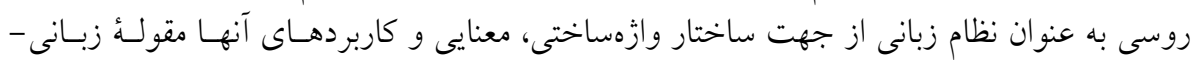

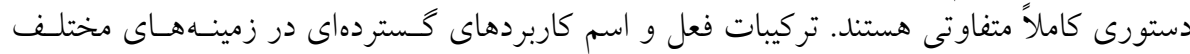

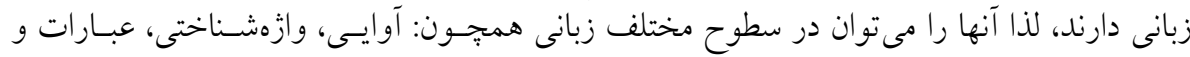

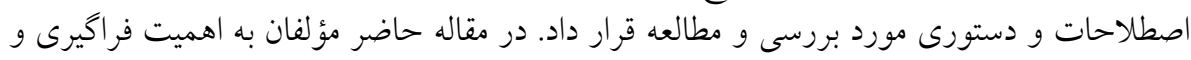

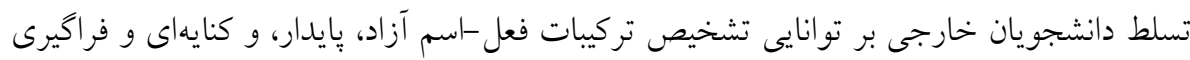

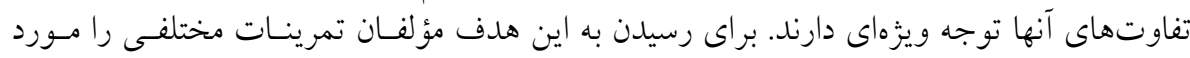

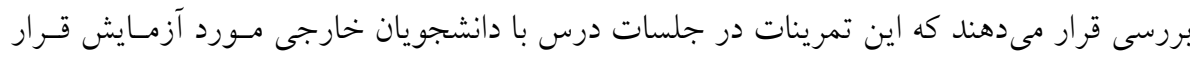

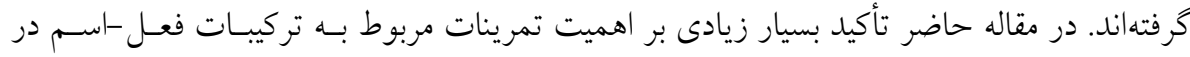

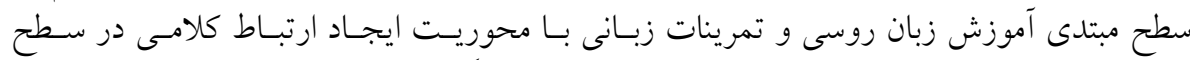

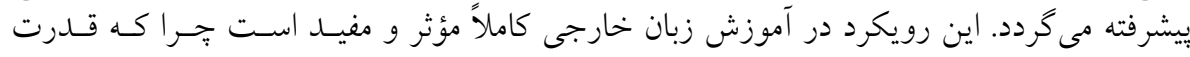

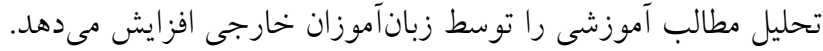

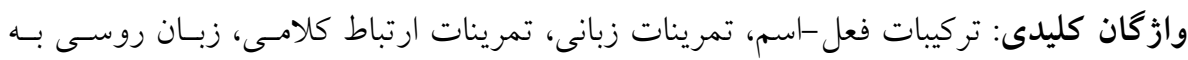

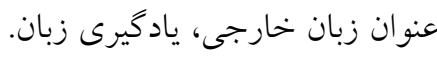

